Check for updates

Cite this: RSC Adv., 2018, 8, 2616

Received 31st October 2017

Accepted 18th December 2017

DOI: $10.1039 / c 7 r a 11964 j$

rsc.li/rsc-advances

\section{Adsorption of tetracycline antibiotics from an aqueous solution onto graphene oxide/calcium alginate composite fibers}

\begin{abstract}
Haotian Zhu, ${ }^{\text {'Tao Chen, }}{ }^{\text {ac }}$ Jingquan Liu (iD *ac and Da Li (iD *ab
In this study, we report the preparation of a novel environmentally friendly and highly efficient adsorbent, graphene oxide/calcium alginate (GO/CA) composite fibers, via a freeze-drying method using calcium chloride as a cross-linking reagent between graphene oxide and sodium alginate. The maximum tetracycline adsorption capacity of the GO/CA composite fibers predicted by the Langmuir model reached $131.6 \mathrm{mg} \mathrm{g}^{-1}$. The adsorption properties of tetracycline onto the fibers were investigated through several parameters including the solution $\mathrm{pH}$, the adsorbent dose, the initial concentration of tetracycline, and the agitation time. The Langmuir and Freundlich adsorption isotherms were used to investigate the adsorption equilibrium. The kinetics of the adsorption process was predicted using the pseudo-first-order and pseudo-second-order kinetic equations. Furthermore, the mechanism of adsorption was investigated, and it was found that the hydrogen bonding and $\pi-\pi$ interaction should serve as predominant contributions to the significantly enhanced adsorption capability.
\end{abstract}

\section{Introduction}

Antibiotics have been used extensively worldwide in human therapy and the farming industry in which they act selectively on bacteria like the pathogens while leaving the human cells and tissues unaffected. ${ }^{1}$ However, they have attracted extensive attention from the scientists because a variety of antibiotics have been detected in soil, surface water, groundwater, and even in drinking water in the recent years. ${ }^{2}$ Antibiotics have been classified as one of the potent pollutants due to their increasing overuse. Since most antibiotics are poorly metabolized and absorbed by the treated humans and animals, large fractions are excreted through urine and feces as an unmodified parent compound., ${ }^{3,4}$ The widespread use of antibiotics has caused a variety of potential adverse effects such as chronic toxicity, lowering of human immunity, ${ }^{5}$ and dissemination into antibiotic-resistant genes. ${ }^{6}$ Antibiotic pollution poses a potential threat to human health. Thus, the removal of antibiotics has become a critical issue.

Tetracycline is one of the most frequently used antibiotics, ranking second in production and usage worldwide. ${ }^{7}$ It has been reported that tetracycline may cause bacterial resistance and thus result in ecological destruction and threaten human

${ }^{a}$ Laboratory of Fiber Materials and Modern Textile, The Growing Base for State Key Laboratory, Qingdao University, Qingdao 266071, PR China.E-mail: d.li@qdu.edu.cn ${ }^{b}$ School of Mechanical and Electronical Engineering, Qingdao University, Qingdao 266071, PR China

${ }^{c}$ School of Materials Science and Engineering, Qingdao University, Qingdao 266071, PR China health through bioaccumulation in the food chain. Therefore, it is urgent to remove tetracycline from water environment. ${ }^{7,8}$

A number of techniques have been developed in the recent years to remove tetracycline from an aqueous solution. These include ozonation, ${ }^{9}$ coagulation, ${ }^{10}$ photo electrocatalytic degradation, ${ }^{11}$ ion exchange, ${ }^{12}$ membrane processing, ${ }^{13}$ and adsorption. ${ }^{14}$ Among them, adsorption is a widely used effective technology due to the advantages of easy operation, low-cost, high efficiency, and no risk of highly toxic byproduct. ${ }^{15}$ The adsorption efficiency is severely affected by the properties, including surface area, porosity, and pore diameter, of an adsorbent and an adsorbate. ${ }^{16}$ Various adsorbents, such as clay and minerals, ${ }^{4,8}$ activated clay, ${ }^{17}$ mats, ${ }^{18-20}$ humic acid, ${ }^{7}$ activated carbon, ${ }^{\mathbf{1 5 , 2 1}}$ carbon nanotubes, ${ }^{\mathbf{2 2 - 2 4}}$ graphene oxide, ${ }^{25}$ and porous hexagonal $\mathrm{BN},{ }^{26}$ have been investigated for adsorption of tetracycline from aqueous solutions.

Graphene, a novel two-dimensional carbon nanomaterial, has attracted significant scientific interest not only due to its applications in electronics and mechanics, ${ }^{27}$ but also due to its adsorption capability. The high theoretical specific surface area $\left(2630 \mathrm{~m}^{2} \mathrm{~g}^{-1}\right)$ of graphene makes it a promising adsorbent for water treatment. Graphene oxide (GO) is a precursor for graphene preparation. Abundant oxygen-containing functional groups, such as epoxy, hydroxyl, and carboxyl groups, are present at the edge or the GO planes, which make GO extremely hydrophilic and provide the capability to be used in the aquatic and biological environment. ${ }^{3}$ However, the application of GO in the removal of tetracycline is currently limited due to its biotoxicity to the human cells. ${ }^{\mathbf{1 4 , 2 8}}$ A key issue in applying GO in 
adsorbing tetracycline is to decrease the dispersibility in the aqueous solutions and the risk of GO to enter the water body.

Sodium alginate, a natural polysaccharide, has been widely used due to its advantages such as low-cost, hydrophilicity, biocompatibility, and nontoxicity. ${ }^{29}$ The molecular chain of sodium alginate is full of hydroxyl and carboxyl acid groups. Upon the exchange of divalent cations with sodium ions, a three-dimensional network can be achieved. Based on the mechanism, calcium chloride was used as a cross-linking agent to prepare the composite of alginate and GO. ${ }^{30}$

In this study, graphene oxide/calcium alginate composite fibers were prepared by a freeze-drying method. The adsorption properties of tetracycline onto the fibers were investigated through several parameters including the solution $\mathrm{pH}$, the adsorbent dose, the initial concentration of tetracycline, and the agitation time. Furthermore, the mechanism of adsorption has been investigated in this study.

\section{Experimental}

\subsection{Materials}

Sodium alginate was purchased from Fuchen Chemical Reagent Factory (Tianjin, China). Expanded graphite was purchased from Henglide Graphite Ltd. (Qingdao, China). Potassium permanganate was obtained from Economic \& Technological Development Zone Fine Chemical Plant (Laiyang, China). Calcium chloride, hydrogen peroxide, sodium nitrate, hydrochloric acid (37\%), and concentrated sulfuric acid were bought from Shanghai Sinopharm Chemical Reagent Co. Ltd. Millipore water $(18 \mathrm{M} \Omega$ ) was used in all the experiments. All chemicals were of reagent grade and used as received.

\subsection{Preparation of graphene oxide}

GO was prepared using a modified Hummers method ${ }^{31}$ (Fig. 1a). Graphite (2 g) was oxidized by concentrated sulfuric acid $(10 \mathrm{~mL})$ and phosphorus(v) oxide $(1 \mathrm{~g})$ at $80{ }^{\circ} \mathrm{C}$. The resultant dark blue mixture was allowed to cool down to room

(a)

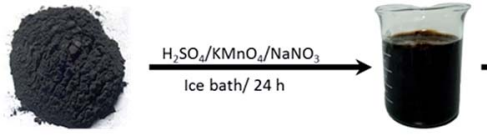
1. 30 min stirring under $35^{\circ} \mathrm{C}$ 2. deionized water 3. 15 min under $98^{\circ} \mathrm{C}$ 4. $\mathrm{H}_{2} \mathrm{O}_{2}(30 \%)$

(b)

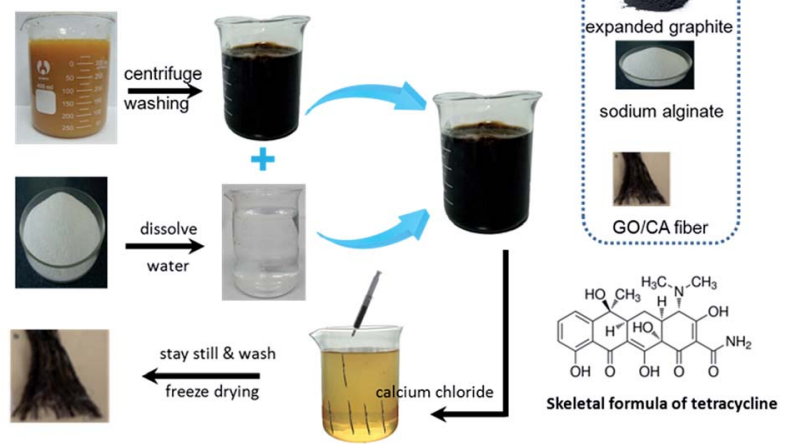

Fig. 1 Preparation of graphene oxide (a) and graphene oxide/calcium alginate fibers (b). temperature. Then, the mixture was diluted, filtered, and washed with distilled water until it became neutral. The preoxidized graphite was then dried and mixed with cold concentrated $\mathrm{H}_{2} \mathrm{SO}_{4}(50 \mathrm{~mL})$, followed by a slow addition of $\mathrm{KMnO}_{4}$ ( $6 \mathrm{~g}$ ) under stirring and cooling to keep the temperature below $20{ }^{\circ} \mathrm{C}$. The solution was then stirred at $35^{\circ} \mathrm{C}$ for $2 \mathrm{~h}$, followed by the addition of distilled water $(400 \mathrm{~mL})$. The reaction was stopped with the addition of a mixture of $280 \mathrm{~mL}$ of distilled water and $5 \mathrm{~mL}$ of $30 \% \mathrm{H}_{2} \mathrm{O}_{2}$ to afford a bright yellow mixture. The product was then dispersed in water, filtered, washed with an aqueous $\mathrm{HCl}$ solution (1: 10), and then dried under vacuum to afford the GO powder.

\subsection{Preparation of graphene oxide/calcium alginate fibers}

Herein, $0.041 \mathrm{~g}$ of GO was dispersed in deionized water and ultrasonicated for $30 \mathrm{~min}$. Then, $100 \mathrm{~mL}$ of a $2 \mathrm{wt} \%$ sodium alginate solution was prepared and kept stirring for 1 hour to exclude air bubbles. The GO dispersion was slowly added to the sodium alginate solution to form a homogeneous mixture. The mixture was then injected into $400 \mathrm{~mL}$ of a $5 \%$ calcium chloride solution using a syringe to afford the GO/CA fibers. After 12 hour still-standing and washing, the GO/CA fibers were finally obtained after vacuum freeze-drying (Fig. 1b).

\subsection{Adsorption experiments}

The adsorption experiments were conducted using the batch equilibration techniques in a temperature-controlled water bath shaker. For the adsorption equilibrium experiments, a fixed adsorbent dose (25 mg) was weighed into $100 \mathrm{~mL}$ conical flasks containing $50 \mathrm{~mL}$ of different initial concentrations of tetracycline. The mixture was shaken for $5 \mathrm{~h}$ at $25{ }^{\circ} \mathrm{C}$ until the equilibrium was obtained. Then, the adsorbent was separated from the solution by centrifugation at $10000 \mathrm{rpm}$ for $5 \mathrm{~min}$. The concentration of tetracycline in the solution was measured using a UV-visible spectrophotometer (TU-1810, Bingjing Puxi Co. Ltd.) at a wavelength of $274 \mathrm{~nm}$. The adsorption capacity was calculated using the following equation:

$$
q_{\mathrm{e}}=\left(\frac{C_{0}-C_{\mathrm{e}}}{W}\right) \times V
$$

where $C_{0}$ and $C_{\mathrm{e}}$ are the initial and equilibrium concentrations of tetracycline $\left(\mathrm{mg} \mathrm{L}^{-1}\right)$, respectively, $m$ is the mass of the adsorbent $(\mathrm{g})$, and $V$ is the volume of the solution $(\mathrm{L})$.

To study the effect of $\mathrm{pH}$ of the tetracycline solution on the adsorption capacity, $10 \mathrm{mg}$ graphene oxide/calcium alginate composite was put in $20 \mathrm{~mL}$ of a $50 \mathrm{mg} \mathrm{L}^{-1}$ tetracycline solution, whose $\mathrm{pH}$ was adjusted from 2 to 9 with an appropriate amount of $\mathrm{HCl}$ and $\mathrm{NaOH}$. Moreover, when the effect of the adsorption dose was investigated, different amounts of $\mathrm{GO} / \mathrm{CA}$ fibers ( 5 to $30 \mathrm{mg}$ ) were added to $20 \mathrm{~mL}$ of a $50 \mathrm{mg} \mathrm{L}^{-1}$ tetracycline solution. Furthermore, when the dynamic adsorption tests were conducted, $200 \mathrm{mg}$ of the fibers was put into $400 \mathrm{~mL}$ of a $50 \mathrm{mg} \mathrm{L}^{-1}$ tetracycline solution, and the concentration of tetracycline was measured at certain time intervals. 


\section{Results and discussion}

\subsection{Characterization of GO and GO/CA}

The graphene oxide solution prepared was bright yellow (Fig. 2a) primarily due to the presence of surface-bound functional groups. By washing with deionized water, the $\mathrm{pH}$ of the dispersion gradually reached neutrality. As a result, the dispersion became darker, as shown in Fig. 2b. The morphologies of GO and GO/CA were examined by an FEI Quanta 200F field emission scanning electron microscope (SEM). The SEM image of graphene oxide is shown in Fig. 2c, from which we can observe many wrinkles. These wrinkles accounted for the large specific surface area and few-layered characteristics, which would enhance the adsorption capability. The SEM images in Fig. 2d and e show that the GO/CA composites have a very rough surface and many strips. Fourier transform infrared (FTIR) spectra were obtained using a Nicolet 5700 FTIR spectrometer (Thermo Electron Corporation, USA) to investigate the structure and functional groups of GO and GO/CA. The FTIR spectrum of GO (Fig. 3a) shows the typical characteristic functional groups of GO: alkoxy C-O $\left(1045 \mathrm{~cm}^{-1}\right)$, epoxy bridges $\mathrm{C}-\mathrm{O}\left(1220 \mathrm{~cm}^{-1}\right)$, the aromatic $\mathrm{C}=\mathrm{C}\left(1615 \mathrm{~cm}^{-1}\right)$ and carboxyl $\mathrm{C}=\mathrm{O}\left(1738 \mathrm{~cm}^{-1}\right)$ bonds, and hydroxy $-\mathrm{OH}\left(3380 \mathrm{~cm}^{-1}\right)$ groups. ${ }^{32}$ After CA was incorporated into GO, compared with GO alone, GO/CA exhibited few changes. This result could be attributed to the relatively small portion of $\mathrm{CA}$ in $\mathrm{GO} / \mathrm{CA}$.

To further demonstrate the carbon-to-oxygen ratio and types of functional groups in GO and GO/CA, XPS was conducted using a Perkin Elmer PHI-5702 multifunctional X-ray photoelectron spectrometer (XPS, Physical Electronics, USA). XPS spectra of GO and GO/CA (Fig. 3b) show the strong $\mathrm{C}$ and $\mathrm{O}$ signals corresponding to the binding energy of GO. The XPS spectrum of GO (Fig. 3c) shows four different groups: $\mathrm{C}=\mathrm{C}$ $(284.5 \mathrm{eV}), \mathrm{C}-\mathrm{C}(285.4 \mathrm{eV}), \mathrm{C}-\mathrm{O}(286.6 \mathrm{eV})$, and $\mathrm{C}=\mathrm{O}(288.8 \mathrm{eV})$. The C/O atomic ratio of GO was measured by XPS to be 1.58 . The XPS spectrum of GO/CA (Fig. 3d) shows the peaks at 282.5, 283.9, 285.3, and $285.9 \mathrm{eV}$, which correspond to $\mathrm{C}-\mathrm{C} / \mathrm{C}-\mathrm{H} / \mathrm{C}=\mathrm{C}$, $\mathrm{C}-\mathrm{O}, \mathrm{C}=\mathrm{O}$, and $\mathrm{O}-\mathrm{C}=\mathrm{O}$, respectively. ${ }^{33}$

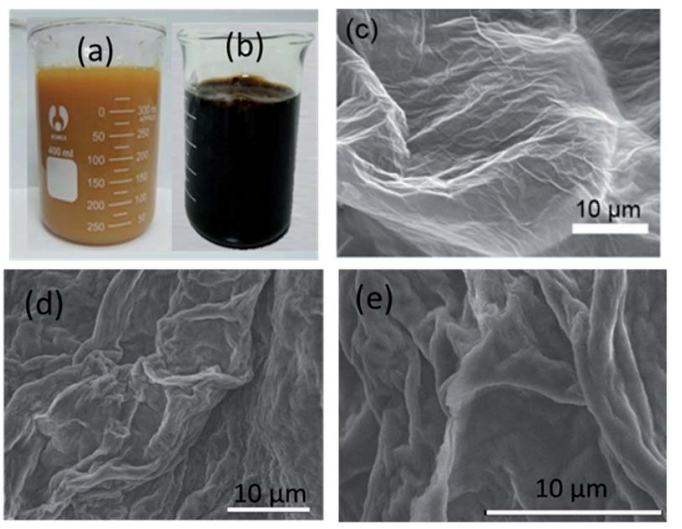

Fig. 2 Optical and SEM images of GO and GO/CA. GO dispersion (a) before and (b) after washing; SEM images of (c) GO and (d) GO/CA, and (e) high magnification of GO/CA in (d).
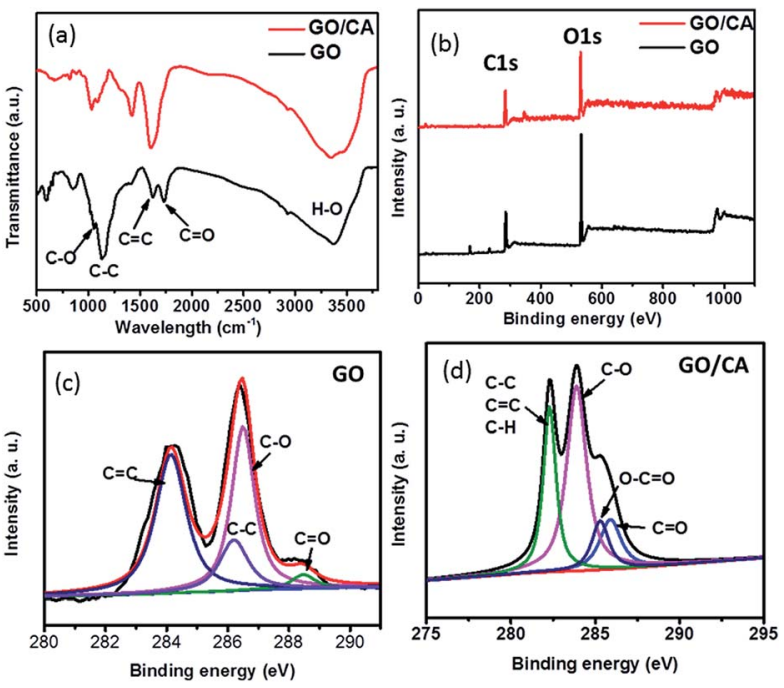

Fig. 3 (a) FTIR spectra of GO and GO/CA, (b) XPS spectra of GO and $\mathrm{GO} / \mathrm{CA}$, (c) C 1s of GO, and (d) C 1s of GO/CA.

\subsection{Effect of the factors of GO/CA on tetracycline adsorption}

3.2.1 Effect of $\mathbf{p H}$. The solution $\mathrm{pH}$ is an important factor that can greatly affect the adsorption process because it can change the surface charge of an adsorbent and its ionization behavior. Fig. 4a shows the effect of the initial $\mathrm{pH}$ on the adsorption of tetracycline onto GO/CA. At $\mathrm{pH}=2.0$, the adsorption capacity of GO/CA is lower $(16.0 \%)$; this can be due to the competition for adsorption sites between tetracycline and $\mathrm{H}^{+}$that locates on the surface of the adsorbent at a low $\mathrm{pH}$. With the increasing $\mathrm{pH}$, the adsorbent gradually gains more adsorption capacity and reaches its maximum adsorption of $56.8 \%$ at $\mathrm{pH}$ 6. Under this nearly neutral condition, the ionization and hydration of tetracycline decrease; this is beneficial for the adsorption process through the hydrogen bonds and the $\pi-\pi$ stacking effect. However, with a further increase in $\mathrm{pH}$, the adsorption capacity of GO/CA fibers tends to decrease slightly;
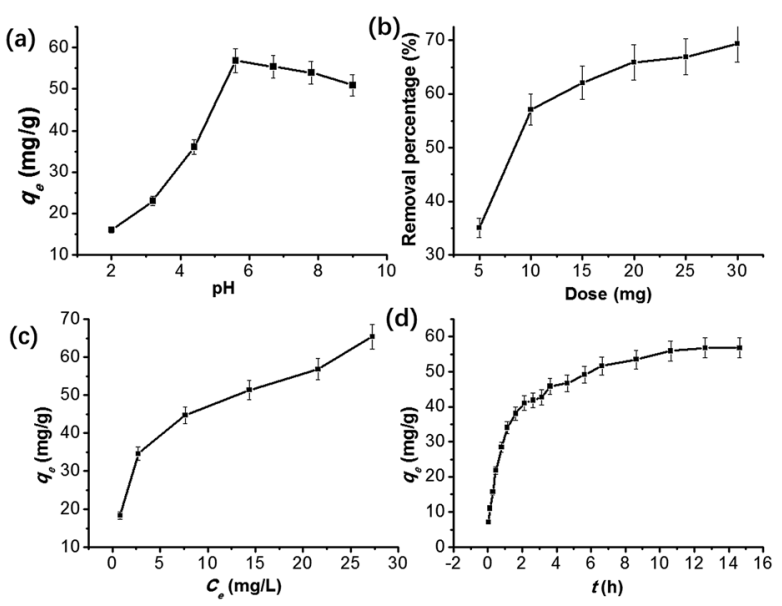

Fig. 4 Effect of different factors on the adsorption of tetracycline on $\mathrm{GO} / \mathrm{CA}$. (a) $\mathrm{pH}$, (b) adsorbent dose, (c) concentration of tetracycline, and (d) agitation time. 
this should be caused by the attenuation of hydrogen bonding due to the generation of $\mathrm{OH}^{-}$.

3.2.2 Effect of the adsorbent dose. Fig. 4b shows the effect of the adsorbent dose on the adsorption capacity of GO/CA for tetracycline. When the dosage of GO/CA is less than $10 \mathrm{mg}$, the removal percentage increases quickly. With a further increase in the adsorbent dose, the adsorption rate slows down due to the saturation of the adsorbate sites. At an initial concentration of tetracycline of $50 \mathrm{mg} \mathrm{L}^{-1}$, the removal percentage of tetracycline was only $35.0 \%$ when the GO/CA dose was $5 \mathrm{mg}$, whereas it reached $69.4 \%$ when the dose was $30 \mathrm{mg}$. It is obvious that the adsorption capacity greatly increases with the increasing adsorbent dose. A possible explanation for this phenomenon is that with the increasing concentration of the adsorbent, more active sites are available for tetracycline; this will effectively abate the competition for a certain adsorption site and thus enhance the adsorption capacity.

3.2.3 Effect of initial concentration of tetracycline. The effect of initial concentration of tetracycline on the adsorption process was studied by the adsorption isotherm, which depicted the relationship between the concentration and the amount of the adsorbate. Fig. 4c shows the adsorption isotherm of GO/CA fibers at different initial tetracycline concentrations. It is obvious that the adsorption capacity increases with the increasing concentration of tetracycline. When the initial concentration of tetracycline was $10 \mathrm{mg} \mathrm{L}^{-1}$, the concentration of tetracycline after the adsorption equilibrium was reached was $1.2 \mathrm{mg} \mathrm{L}^{-1}$, and the adsorption capacity of GO/CA fibers reached $17.6 \mathrm{mg} \mathrm{g}^{-1}$. When the initial concentration reached $60 \mathrm{mg} \mathrm{L}^{-1}$, the equilibrium concentration increased to $27.3 \mathrm{mg} \mathrm{L}^{-1}$, and the adsorption capacity increased to $65.4 \mathrm{mg} \mathrm{g}^{-1}$.

Then, the isotherm data were analyzed by fitting them to distinctive isotherm models to determine an appropriate model for the adsorption process. Langmuir and Freundlich models, two most frequently used models in adsorption, have been chosen to fit the experimental data.

The Langmuir model assumes that the adsorption occurs on an even monolayer surface with no layer interaction. The Langmuir isotherm equation can be expressed as follows: ${ }^{34}$

$$
\frac{C_{\mathrm{e}}}{q_{\mathrm{e}}}=\frac{C_{\mathrm{e}}}{q_{\max }}+\frac{1}{q_{\max } k_{\mathrm{L}}}
$$

where $C_{\mathrm{e}}\left(\mathrm{mg} \mathrm{L}^{-1}\right)$ is the solution concentration at the adsorption equilibrium, $q_{\max }\left(\mathrm{mg} \mathrm{g}^{-1}\right)$ is the maximum adsorption capacity, and $k_{\mathrm{L}}\left(\mathrm{L} \mathrm{g}^{-1}\right)$ is a Langmuir constant related to the affinity of the binding sites and the energy of adsorption.

The data are then analyzed by fitting with a non-linear Langmuir equation, and $q_{\max }$ and $k_{\mathrm{L}}$ can be calculated by the

Table 1 Constants of Langmuir and Freundlich isotherms

\begin{tabular}{|c|c|c|c|c|c|c|}
\hline \multirow[b]{2}{*}{$\begin{array}{l}\text { Temperature } \\
\left({ }^{\circ} \mathrm{C}\right)\end{array}$} & \multicolumn{3}{|l|}{ Langmuir } & \multicolumn{3}{|c|}{ Freundlich } \\
\hline & $\begin{array}{l}q_{\max } \\
\left(\mathrm{mg} \mathrm{g}^{-1}\right)\end{array}$ & $\begin{array}{l}k_{\mathrm{L}} \\
\left(\mathrm{L} \mathrm{g}^{-1}\right)\end{array}$ & $R^{2}$ & $\begin{array}{l}k_{\mathrm{F}} \\
\left(\mathrm{L} \mathrm{g}^{-1}\right)\end{array}$ & $1 / n$ & $R^{2}$ \\
\hline 25 & 131.57 & 0.11 & 0.9938 & 16.11 & 0.41 & 0.9986 \\
\hline
\end{tabular}

slope and the intercept of the fitting line (Table 1). The coefficient $R^{2}=0.9938$ of Langmuir equation means that the adsorption of tetracycline on GO/CA fibers fits the Langmuir model. The maximum adsorption capacity $q_{\max }$ of tetracycline on $\mathrm{GO} / \mathrm{CA}$ fibers at $25{ }^{\circ} \mathrm{C}$ was calculated to be $131.6 \mathrm{mg} \mathrm{g}^{-1}$.

The Freundlich equation is an empirical equation for a single solute system based on a heterogeneous surface. The Freundlich equation can be written as follows:

$$
\ln q_{\mathrm{e}}=\ln k_{\mathrm{F}}+\frac{1}{n} \ln C_{\mathrm{e}}
$$

Where $k_{\mathrm{F}}\left(\mathrm{L} \mathrm{g}^{-1}\right)$ is a Freundlich constant related to the adsorption capacity, and $\frac{1}{n}$ is an empirical parameter related to the adsorption intensity. The scatter plots are then analyzed to obtain the value of $n$ and $k_{\mathrm{F}}$ (Table 1). The coefficient $R^{2}=0.9986$ of the Freundlich equation denotes that the adsorption of tetracycline on GO/CA fibers fits the Freundlich model as well.

3.2.4 Effect of the agitation time. Fig. $4 \mathrm{~d}$ shows the effect of the agitation time on the adsorption of tetracycline on GO/CA at an initial tetracycline concentration of $50 \mathrm{mg} \mathrm{L}^{-1}$. It is obvious that the adsorption capacity of GO/CA is much higher in the first two hours; this indicates a much higher affinity between the tetracycline molecules and the GO/CA surface. After $2 \mathrm{~h}$, the adsorption capacity gradually slowed down until the adsorption process reached an equilibrium $\left(56.8 \mathrm{mg} \mathrm{g}^{-1}\right)$ in $15 \mathrm{~h}$.

\subsection{Kinetic studies}

The pseudo-first-order and pseudo-second-order were applied to evaluate the kinetic mechanism of the adsorption process. The pseudo-first-order rate model is shown as follows: ${ }^{35}$

$$
\log \left(q_{\mathrm{e}}-q_{t}\right)=\log q_{\mathrm{e}}-\frac{k_{1}}{2.303} t
$$

where $k_{1}\left(\min ^{-1}\right)$ is the adsorption rate constant and $q_{\mathrm{e}}$ and $q_{t}$ $\left(\mathrm{mg} \mathrm{g}^{-1}\right)$ are the adsorption capacity at equilibrium and at time $t$ (min), respectively. The values of $k_{1}$ can be determined from the slope of the plot of $\log \left(q_{\mathrm{e}}-q_{t}\right)$ versus $t$. The values of the kinetic parameters are listed in Table 2 . The $R^{2}$ value was derived to be less than 0.91 , indicating that the adsorption process did not fit the pseudo-first-order rate model.

The pseudo-second-order rate model is expressed as follows: ${ }^{36}$

$$
\frac{t}{q_{t}}=\frac{1}{2 k_{2} q_{\mathrm{e}}^{2}}+\frac{t}{q_{\mathrm{e}}}
$$

Table 2 Kinetic fitting parameters of pseudo-first-order and pseudosecond-order models for the adsorption of tetracycline onto GO/CA

\begin{tabular}{lll}
\hline Kinetic model & Parameters & Values \\
\hline Pseudo-first order & $k_{1}\left(\mathrm{~min}^{-1}\right)$ & 0.45 \\
& $q_{\mathrm{e}}\left(\mathrm{mg} \mathrm{g}^{-1}\right)$ & 40.93 \\
& $R^{2}$ & 0.9020 \\
Pseudo-second & $k_{2}\left(\mathrm{~g} \mathrm{mg}^{-1} \mathrm{~min}\right)$ & $23.27 \times 10^{-3}$ \\
order & $q_{\mathrm{e}}\left(\mathrm{mg} \mathrm{g}^{-1}\right)$ & 62.50 \\
& $R^{2}$ & 0.9990
\end{tabular}




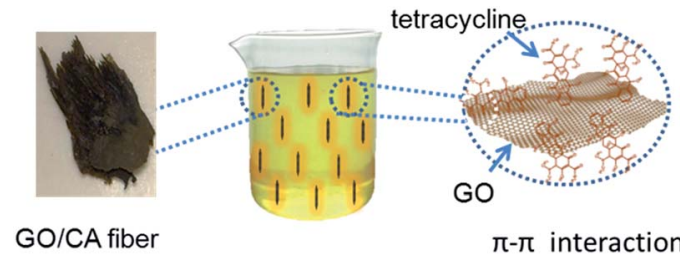

Fig. 5 Mechanism of the adsorption of tetracycline on GO/CA composite fibers.

where $k_{2}\left(\mathrm{~g} \mathrm{mg}^{-1} \mathrm{~min}^{-1}\right)$ is the adsorption rate constant $\left(\mathrm{g} \mathrm{mg}{ }^{-1} \mathrm{~min}^{-1}\right) . k_{2}$ can be determined from the intercept of the plot of $t / q_{t}$ versus $t$. The correlation coefficients of $R^{2}$ are much higher than those in the pseudo-first-order model; this indicates that the adsorption of tetracycline onto GO/CA fits the pseudo-second-order rate model.

\subsection{Discussion of adsorption mechanism}

Due to the existence of large amounts of oxygen-containing functional groups (such as $-\mathrm{COOH}$ and $-\mathrm{OH}$ ) on the surface of GO/CA fibers, the tetracycline molecules can be firmly adsorbed onto the fibers through hydrogen bonding and the intermolecular forces between the amino groups $\left(-\mathrm{NH}_{2}\right)$ on tetracycline and the oxygen-containing functional groups on GO. Moreover, the cations in the tetracycline solution may easily combine with the anions on the GO/CA fiber surface through ionic bonding; this leads to the enhanced adsorption capability. Furthermore, both tetracycline molecules and GO/CA fibers possess benzene rings and double bonds $(\mathrm{C}=\mathrm{C}$ and $\mathrm{C}=\mathrm{O})$, which will result in a possible $\pi-\pi$ stacking interaction. ${ }^{37}$ All these factors will lead to significantly enhanced adsorption of tetracycline onto GO/CA fibers.

The main adsorption mechanism of tetracycline (e.g. chlortetracycline, oxytetracycline, and tetracycline) includes hydrogen bonding and $\pi-\pi$ interactions (Fig. 5). The tetracycline molecules possess amino groups and carbon radicals etc., which are suitable for the formation of hydrogen bonds with carboxyl and hydroxyl groups on the surface of the GO/CA fibers. There also exists aromatic structures and $\mathrm{C}=\mathrm{C}$ double bonds in tetracycline, which will also contribute to the affinity between graphene-conjugated basal planes and tetracycline through the $\pi-\pi$ interactions and finally increase the adsorption capability.

\section{Conclusions}

A novel environmentally friendly and highly efficient adsorbent, a graphene oxide/calcium alginate composite fiber, was prepared by a freeze-drying method. The GO/CA fibers exhibited a high adsorption capability towards tetracycline, and the maximum adsorption capacity calculated by Langmuir model could reach $131.6 \mathrm{mg} \mathrm{g}^{-1}$. The adsorbent showed its maximum adsorption capacity at $\mathrm{pH}$. The maximum adsorption capacity increased with an increase in the adsorbent dose, the initial concentration of tetracycline, and the agitation time. It is also found that the adsorption of tetracycline onto GO/CA follows the pseudo-second-order model; this means that the tetracycline adsorption process is controlled by the intra-particle diffusion. In the process of adsorption of aromatic compounds onto graphene oxide, $\pi-\pi$ interaction, hydrogen bonding, and electrostatic affinity play a significant role in increasing the adsorption capability of the graphene oxide/ calcium alginate composite.

\section{Conflicts of interest}

There are no conflicts of interest to declare.

\section{Acknowledgements}

The work was supported by the Natural Science Foundation of Shandong Province (ZR201702210208) and a project of Shandong Province Higher Educational Science and Technology Program (J17KA103). The authors would like to thank Prof. Yanhui Li for the discussion on the adsorption mechanism.

\section{Notes and references}

1 M. B. Ahmed, J. L. Zhou, H. H. Ngo and W. Guo, Sci. Total Environ., 2015, 532, 112.

2 C. Adams, M. Asce, Y. Wang, K. Loftin and M. Meyer, J. Environ. Eng., 2002, 128, 253-260.

3 Y. Gao, Y. Li, L. Zhang, H. Huang, J. Hu, S. M. Shah and X. Su, J. Colloid Interface Sci., 2012, 368, 540-546.

4 U. A. Guler and M. Sarioglu, J. Environ. Health Sci. Eng., 2014, 12, 79.

5 O. A. Jones, J. N. Lester and N. Voulvoulis, Trends Biotechnol., 2005, 23, 163-167.

6 L. Aristilde, C. Marichal, J. Miéhé-Brendlé, B. Lanson and L. Charlet, Environ. Sci. Technol., 2010, 44, 7839-7845.

7 C. Gu, K. Karthikeyan, S. D. Sibley and J. A. Pedersen, Chemosphere, 2007, 66, 1494-1501.

8 Y. Guo, W. Huang, B. Chen, Y. Zhao, D. Liu, Y. Sun and B. Gong, J. Hazard. Mater., 2017, 339, 22.

9 M. H. Khan, H. Bae and J.-Y. Jung, J. Hazard. Mater., 2010, 181, 659-665.

10 N. Li, G. P. Sheng, Y. Z. Lu, R. J. Zeng and H. Q. Yu, Water Res., 2017, 111, 204-212.

11 Y. Liu, X. Gan, B. Zhou, B. Xiong, J. Li, C. Dong, J. Bai and W. Cai, J. Hazard. Mater., 2009, 171, 678-683.

12 Y. J. Wang, D. A. Jia, R. J. Sun, H. W. Zhu and D. M. Zhou, Environ. Sci. Technol., 2008, 42, 3254-3259.

13 I. Koyuncu, O. A. Arikan, M. R. Wiesner and C. Rice, J. Membr. Sci., 2008, 309, 94-101.

14 Y. Li, Q. Du, T. Liu, J. Sun, Y. Wang, S. Wu, Z. Wang, Y. Xia and L. Xia, Carbohydr. Polym., 2013, 95, 501-507.

15 M. J. Ahmed, Environ. Toxicol. Pharmacol., 2017, 50, 1.

16 F. Yu, Y. Li, S. Han and J. Ma, Chemosphere, 2016, 153, 365385.

17 C. H. Weng and Y. F. Pan, J. Hazard. Mater., 2007, 144, 355362.

18 S. Xin, X. Li, Q. Wang, R. Huang, X. Xu, Z. Lei and H. Deng, J. Biomed. Nanotechnol., 2014, 10, 803-810. 
19 S. Xin, Z. Zeng, X. Zhou, W. Luo, X. Shi, Q. Wang, H. Deng and Y. Du, J. Hazard. Mater., 2017, 324, 365-372.

20 Y. Lu, X. Li, X. Zhou, Q. Wang, X. Shi, Y. Du, H. Deng and L. Jiang, RSC Adv., 2014, 4, 33355-33361.

21 K. J. Choi, S. G. Kim and S. H. Kim, J. Hazard. Mater., 2008, $151,38$.

22 L. Ji, W. Chen, L. Duan and D. Zhu, Environ. Sci. Technol., 2009, 43, 2322-2327.

23 L. Ji, W. Chen, L. Duan and D. Zhu, Environ. Sci. Technol., 2009, 43, 2322.

24 L. Jiang, H. Tu, Y. Lu, Y. Wu, J. Tian, X. Shi, Q. Wang, Y. Zhan, Z. Huang and H. Deng, Chem. Phys. Lett., 2016, 650, 82-87.

25 K. Ouyang, C. Zhu, Y. Zhao, L. Wang, S. Xie and Q. Wang, Appl. Surf. Sci., 2015, 355, 562-569.

26 Q. Song, Y. Fang, Z. Liu, L. Li, Y. Wang, J. Liang, Y. Huang, J. Lin, L. Hu and J. Zhang, Chem. Eng. J., 2017, 325, 71-79.

27 D. Li, J. Liu, C. J. Barrow and W. Yang, Chem. Commun., 2014, 50, 8197-8200.
28 K. H. Liao, Y. S. Lin, C. W. Macosko and C. L. Haynes, ACS Appl. Mater. Interfaces, 2011, 3, 2607.

29 Y. Liu, S. Chen, L. Zhong and G. Wu, Radiat. Phys. Chem., 2009, 78, 251-255.

30 B. Sarmento, S. Martins, A. Ribeiro, F. Veiga, R. Neufeld and D. Ferreira, Int. J. Pept. Res. Ther., 2006, 12, 131-138.

31 W. S. Hummers and R. E. Offeman, J. Am. Chem. Soc., 1958, 80, 1339.

32 J. Chen, B. Yao, C. Li and G. Shi, Carbon, 2013, 64, 225-229.

33 Y. Fei, Y. Li, S. Han and J. Ma, J. Colloid Interface Sci., 2016, 484, 196-204.

34 I. Langmuir, J. Chem. Phys., 2015, 40, 1361-1403.

35 D. Karadag, M. Turan, E. Akgul, A. Sema Tok and A. Faki, J. Chem. Eng. Data, 2007, 52, 1615-1620.

36 Y. S. Ho and C. C. Chiang, Adsorption, 2001, 7, 139-147.

37 B. Peng, L. Chen, C. Que, K. Yang, F. Deng, X. Deng, G. Shi, G. Xu and M. Wu, Sci. Rep., 2016, 6, 31920. 